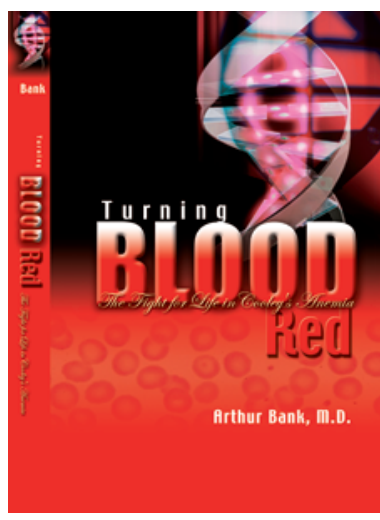

\title{
Turning blood red
}

The fight for life in Cooley's anemia

\author{
Arthur Bank \\ World Scientific Publishing Company. Hackensack, New Jersey, USA. 2008. \\ 288 pp. \$39.95. ISBN: 978-981-283-247-4 (hardcover).
}

\section{Reviewed by David G. Nathan}

Dana-Farber Cancer Institute, Harvard Medical School, Boston, Massachusetts, USA.

E-mail: david_nathan@dfci.harvard.edu

B -Thalassemia (also known as Cooley's anemia or Mediterranean anemia) is an inherited autosomal anemia resulting from genetic mutations that reduce the rate of synthesis of $\beta$-globin chains of hemoglobin, the oxygen-carrying protein in red blood cells. This anemia, if untreated, can result in heart failure, hepatosplenomegaly, and adverse skeletal changes. Periodic blood transfusions over the patient's lifetime usually result in fatal iron overload. Interestingly, and for reasons that still remain elusive, $\beta$-thalassemia provides partial protection against infection with certain species of Plasmodium parasites - the mosquito-borne agents that cause malaria. The disease is particularly prevalent among Mediterranean, African, and Southeast Asian populations that evolved in regions where malaria was and may remain endemic.

In the late 19 th and early 20th centuries, New York City received thousands of immigrants from southern Italy and Greece. They brought with them their remarkable culinary, musical, stone-crafting, and horticultural skills together with a high incidence of mutations and deletions in the $\beta$-globin gene locus. A number of these individuals made their way to Detroit, where they encountered Thomas Cooley, who first described the disease in an English-language medical journal as a unique form of "erythroblastic anemia." Carl Smith, a general pediatrician at Cornell University who became one of the early pediatric hematologists, established one of the first special clinics for the care of patients with $\beta$-thalassemia, and it was the patients seen at that clinic who attracted the attention of Arthur Bank, author of Turning blood red: the fight for life in Cooley's anemia.

In Turning blood red, Bank, who today is director of the Division of Hematology and a professor in the Department of Medicine as well as the Department of Genetics and Development at New York's Columbia University, offers a mélange of a laboratory memoir, brief accounts of the beleaguered lives of six Cooley's anemia patients and their families, a necessarily truncated review of disease pathophysiology and treatment, and a tribute to a devoted support group, the Cooley's Anemia Foundation (www.thalassemia.org). Bank has played an important role in this organization, particularly in its early days, and currently serves as a member of its Medical Advisory Board.

With limited space available, Turning blood red provides few details of the evolution of our understanding of the scientific underpinnings of Cooley's anemia, and some researchers may find that the contributions they made to the field are barely, if at all, mentioned. But Bank's intent was to write about his own career, his contributions to our understanding of this inherited blood disease, and the associates with whom he worked. His book is directed toward multiple audiences, including himself, his family and colleagues, patients and their families, potential financial donors and supporters, and perhaps, medical and nursing students who desire an overview of one of the most devastating diseases worldwide. After all, thalassemia and the inherited red blood cell disorder sickle cell disease (in which synthesized globin chains function incorrectly), though rela- tively uncommon in this country, constitute huge public health burdens in less developed regions of the world. In fact, together they rank third, below infection and malnutrition, in terms of their costs to society in geographical areas that constitute the old malarious belt. That statistic may change as cancer and coronary artery disease emerge as major killers in the rapidly westernizing countries of the ancient (and unfortunately persistent) malaria zone.

In this reviewer's opinion, Bank insufficiently comprehends the central issues that arose in a battle that broke out in the 1990s over the clinical use of an orally active iron chelator for the treatment of iron overload in patients with thalassemia, during which a pharmaceutical company developing the drug at that time is reported to have tried to suppress publication of an investigator's negative opinions about the drug's safety and efficacy.

Physicians who write about their research or clinical experiences for a public audience often have limited proficiency in the treatment of dialogue or the skillful weaving of personal, scientific, and clinical messages into gripping prose that readers of the medical writings of Berton Roueche, Jerome Groopman, or Atul Gawande have come to enjoy. But Turning blood red is a workmanlike account of a physician's commitment to a disease and particularly to the patients and their families who endure it. Bank does understand that patients with thalassemia and their families are among the real heroes of the molecular biology revolution in medicine. We owe them our profound allegiance, and this book makes that case. 